\title{
Correction to: Invasive group A Streptococcus disease in Australian children: 2016 to 2018 - a descriptive cohort study
}

Jane Oliver ${ }^{1,2^{*}}$, Elise Thielemans ${ }^{1,3}$, Alissa McMinn ${ }^{1}$, Ciara Baker ${ }^{1}$, Philip N. Britton ${ }^{4,5}$, Julia E. Clark ${ }^{6}$, Helen S. Marshall ${ }^{7}$, Christopher C. Blyth ${ }^{8,9,10}$, Joshua Francis ${ }^{11,12}$, Jim Buttery ${ }^{1,13}$, Andrew C. Steer ${ }^{1}$, Nigel W. Crawford ${ }^{1,2}$ and on behalf of the PAEDS investigators

\section{Correction to: BMC Public Health 19, 1750 (2019) https://doi.org/10.1186/s12889-019-8085-2}

It was highlighted that the original article [1] contained an error in rates in the section "Annualised minimum incidence rate of paediatric iGAS disease". This Correction article shows the incorrect and correct sentence. The authors would like to apologize to the readers for the inconvenience. The original article has been updated.

\section{Incorrect}

The mean annualised minimum incidence rate for ATSI children ( $<18$ years old) across the study period was 6.7 (95\% CI: 4.0-11.1)/100,000, 4.1-fold higher than for all children (1.6, 95\% CI: 1.1-2.3/100,000).

\section{Correct}

The mean annualised minimum incidence rate for ATSI children ( $<18$ years old) across the study period

was 3.4 (95\% CI: 2.1-5.7)/100,000, 2.1-fold higher than for all children (1.6, 95\% CI: 1.1-2.3/100,000).

\section{Author details}

${ }^{1}$ Murdoch Children's Research Institute, Royal Children's Hospital, Flemington Rd, Parkville, Victoria 3052, Australia. ${ }^{2}$ The Peter Doherty Institute for Infection and Immunity, University of Melbourne, Melbourne, Victoria, Australia.

${ }^{3}$ Université Libre de Bruxelles, Bruxelles, Belgium. ${ }^{4}$ The Children's Hospital at Westmead, Sydney, Australia. ${ }^{5}$ Medical School University of Sydney, Sydney, New South Wales, Australia. ${ }^{6}$ Queensland Children's Hospital, and School of Clinical Medicine, University of Queensland, Brisbane, Queensland, Australia. ${ }^{7}$ Women's and Children's Hospital, Adelaide, South Australia, Australia. ${ }^{8}$ School of Medicine angeid Telethon Kids Institute, University of Western Australia, Perth, Australia. ${ }^{9}$ Perth Children's Hospital, Perth, Western Australia, Australia. ${ }^{10}$ PathWest Laboratory Medicine, Nedlands, Perth, Australia. ${ }^{11}$ Royal Darwin Hospital, Darwin, Northern Territory ", Australia. ${ }^{12}$ Menzies School of Health Research, Darwin, Northern Territory "A Australia. ${ }^{13}$ Monash Health, Monash University, Melbourne, Victoria, Australia.

Published online: 03 May 2021

\section{Reference}

1. Oliver J, et al. Invasive group A Streptococcus disease in Australian children: 2016 to 2018 - a descriptive cohort study. BMC Public Health. 2019;19:1750. https://doi.org/10.1186/s12889-019-8085-2.

* Correspondence: jane.oliver@mcri.edu.au

'Murdoch Children's Research Institute, Royal Children's Hospital, Flemington Rd, Parkville, Victoria 3052, Australia

${ }^{2}$ The Peter Doherty Institute for Infection and Immunity, University of Melbourne, Melbourne, Victoria, Australia

Full list of author information is available at the end of the article

(c) The Author(s). 2021 Open Access This article is licensed under a Creative Commons Attribution 4.0 International License, which permits use, sharing, adaptation, distribution and reproduction in any medium or format, as long as you give appropriate credit to the original author(s) and the source, provide a link to the Creative Commons licence, and indicate if changes were made. The images or other third party material in this article are included in the article's Creative Commons licence, unless indicated otherwise in a credit line to the material. If material is not included in the article's Creative Commons licence and your intended use is not permitted by statutory regulation or exceeds the permitted use, you will need to obtain permission directly from the copyright holder. To view a copy of this licence, visit http://creativecommons.org/licenses/by/4.0/ The Creative Commons Public Domain Dedication waiver (http://creativecommons.org/publicdomain/zero/1.0/) applies to the data made available in this article, unless otherwise stated in a credit line to the data. 